MISCELLANEA
GEOGRAPHICA

Vol. 13/2008

pp. 169-175

\section{Robert Łuczak}

University of Warsaw - Faculty of Geography and Regional Studies

- Institute of Regional and Global Studies, 00-927 Warsaw, Krakowskie Przedmieście 30

e-mail:rluczak@uw.edu.pl

\title{
DISTANT YET LINKED PLACES \\ - A THEORETICAL OUTLOOK ON GEOGRAPHY OF CONTEMPORARY ECONOMIC ACTIVITY
}

\begin{abstract}
As number of studies show, Information and Communication Technologies (ICT) have become important factor of economic activity worldwide.

This article presents a proposal of a theoretical approach to contemporary geography of economic activity - a phenomena narrowed here to business processes usually referred to as information or knowledge-based sector of the economy. The reasoning is based on a theoretical model presented by Michael Storper that has been developed further. The output shows the existence of a distinctive paradox of digital era: the ICT potentially being able to overcome spatial barriers, lead to refocusing on spatial dimension of business. It is concluded that ICT introduce new dimension of division of business process and labor, namely a spatial one. It is leading to worldwide reconfiguration of the geography of economic activity developed under fordist regime of production - hitherto separate areas and territories are being transformed into network economy of distant yet linked places.
\end{abstract}

Key words: information economy, information and communication technologies, spatial division of labor, agglomeration, offshoring, outsourcing, network economy

Mark E. Hepworth opens up his book Geography of the Information Economy published in 1990 with the following passage:

"Advanced industrialized economies are in the midst of an 'information revolution', whose geography will determine the future development prospects of the cities, regions and countries we live in." (Hepworth 1990: 1) 
The tone of the above quotation now, that is 17 years after its publication, sounds a little bit pompous. The newly emerged geography of the information economy does not determine the pattern of development by itself. Nevertheless, Information and Communication Technologies (ICT) clearly influence the organization of economic activities and social life. This issue has been a subject to number of both theoretical and empirical studies - the list is long and covers majority of fields of human activity, as well as broad geographical scope. Within the field of economy, the changes introduced by ICT have been discussed since 1970s. The important achievement in thinking of new economic paradigm was the introduction of the idea of "informational mode of production" by Manuel Castells (Castells 1989). What needs to be recalled here, is that the information economy is not the same as post-industrial one. Whereas societies of well developed countries are growingly engaged in post-industrial economic activities ${ }^{1}$, the industrial production does not disappear from the world economy. It has been shifted to less developed regions, yet decent share of services being provided in more developed regions are partially or completely connected to the production of goods (e.g. R\&D, management, financial services, IT development and support, customer service, etc.). These services are part of production process, but they require appropriate labor, institutions and infrastructure that are available in more developed regions. However, the informational mode of production is also constituted by high-end services that are not part of any concrete production process directly (e.g. education, medicine, governance, etc.). Hence, information economy should not be confused with post-industrial, that is service, one. The latter is a sector of the economy, whereas the first one reminds more of a horizontal layer overwhelming traditional sectors - elements of informational mode of production can be found in agriculture, manufacturing, and in services. Within the information economy, it is also possible to single out knowledge-based economy - narrower fragment of the phenomena specifically devoted to production of new knowledge. The knowledge-based or knowledge-driven economy is in the very core of information revolution, but it is important not to confuse it with the broader phenomena of information economy.

${ }^{1}$ In 2000 in 24 high-income (above 10276.00 USD GDP per capita) OECD member states the components of GDP were the following: 1.8\% (agriculture), 27.8\% (manufacturing), 70.4\% (services) (World Bank, http://www.worldbank.org). 
The information economy is constituted by couple of basic characteristics: it is focused on information - its production, transformation and distribution; it deals with dematerialized and digitized matters; its products can be distributed through the communication networks. The above set clearly proves that the coming of information economy is directly bounded with the development of ICT. These technologies constitute the backbone of the information economy and - as it has been proved - there is a correlation between the increase of information-based activities and the development and diffusion of ICT (Foray 2004). The technologies allow for the construction of information flows not only across economic sectors, as it has been said before, but also between various geographical regions. Nowadays, it is possible to exchange any piece of information between most distant places. The super-territorial connections organized on the basis of ICT are one of the characteristics of the contemporary phase of social and economic development (Scholte 2006). This is where geographical perspective starts playing vital role.

In early works regarding the influence of ICT on economy, the most common perspective focused on couple of major points:

- firstly, ICT allow for low-cost production, storage, transformation and distribution of information that leads to increasing productivity and lowering the transaction and transportation costs (Carayannis \& Sipp, 2006);

- secondly, ICT allow for undertaking economic activity, especially providing services, on a distance (Ibid.);

- finally, ICT allow for decentralization of economic activity by spatial division of the production processes within space (Castells 1989). Also from management and business organization perspective, the ICT are usually seen as the tool of spreading out economic activity. These technologies give companies a chance to make decisions about location of production site of each element of added value chain in a very flexible manner (Yip 2004). Therefore, theoretically ICT give us a unique chance to overcome spatial barriers in distribution of information and in location of information economy entities. Within this frame of reference, ICT are the tool of de-concentration of information-based economic activity.

Having said that, it is possible to construct a theoretical outlook on geography of contemporary economic activity based on ICT, in order to test the above reasoning. To do it, we will use a model presented 
by Michael Storper. Storper introduces an imagined "flow-substitution economy", where "resources would flow between parts of a firm, between places, without having any particular dependence on any particular place" (Storper 2000: 44).

In this model, the homogenous space hosts an economy that is entirely based on flows built upon ICT. In a situation like this, all locations in a given space are equally attractive for locating economic activity. We can make an assumption then, that certain activity of one given firm is decided to be located in point A. Theoretically, all other firms that compete with each other could locate the same type of activity in a different location. However, as it has been recognized by number of authors, as soon as one firm decides to locate its activity in point A, agglomeration processes are being initiated and, in consequence, agglomeration advantages are being produced in this particular location. If the location of economic activity influences neither the production, nor the distribution, nor the consumption, it makes more sense for all other firms to locate it where it is already present. In our example it is in point A, where labor is already trained, elements of infrastructure are in place and institutional capacity is being built - maybe only to some extent, but definitely point A is already relatively better suited to host given activity than any other place. Therefore, all other firms, despite the unlimited spatial choice they have, will locate their activity in the same point A. Such situation leads directly to spatial concentration of a given activity in one point. Therefore, the assumption of a homogenous space where the assets (information) can be located freely, results in coming of the location pattern where economic activity is not distributed equally, but completely concentrated.

If this reasoning is continued further and more types of economic activity are taken into account, the output continues to show paradoxical nature of ICT and flow-based economy. Two scenarios are most likely. In the first and extreme one whole of global supply comes from a single place. This would be a direct consequence of progressive and continuous concentration of all kinds of economic activity in one location. This scenario is underpinned by the same logic as the example introduced by Storper - lack of transaction and transportation costs echoing distance results in the absolute dominance of agglomeration processes and advantages they produce. In the second scenario, each type of economic activity has its own center - point of concentration. In this case homogenous, equally accessible space that served 
as a basis for this argumentation is being transformed into highly polarized space, where selected points are specialized hosts of selected types of economic activity. Such business location pattern is possible due to the nature of the economy under study - one based on superterritorial flows. In economy organized in this manner, finalizing the production process, that is going through each stage of the process, means shifting from one location to another. Therefore, the production is executed globally (not in one location) - it is divided into number of stages that take place in different locations.

As one can see, complete overcoming spatial obstacles in this theoretical modeling does not lead to de-concentration of economic activity and its equal distribution across given space, but to complete concentration (first scenario) or to polarization and construction of a network economy (second scenario).

In reality such a homogenous space as described above does not exist. The socio-economic space as we live in has been shaped throughout history and certain places (or regions) have gained particular comparative and competitive advantages. Based on them they attract given piece of global production process. They are able to do it due to ICT and the super-territorial flows they constitute within the information economy.

Presently, the observation of the world economy suggests that the location decisions are taken in accordance with the theoretical location pattern described above. Recent growth of location-related economic phenomena known as offshoring and outsourcing proves the theoretical analysis. ICT-based information economy gives firms unique chance to make such location decisions, so they maximize benefits from advantages and specificity offered by concrete locations. This framework forces different places and regions to compete for certain investments that would allow them to become nodes in the network economy. The worldwide recognized cases such as: Silicon Valley as new technologies and innovation center, Bangalore as IT and software development center, New York, London Tokyo and Singapore as financial centers, demonstrate this pattern in working. These are only basic examples, yet it can be observed that contemporary economy is focused around relatively few specialized locations that concentrate the most important parts of business processes. These places due to historically or politically rooted advantages and specificities are immune to substitution by another place. Agglomeration processes strengthen their attrac- 
tiveness on global market of places and, in parallel, ICT allow firms located there to generate information-rich supply and distribute it globally. Hence, the information economy is a global phenomena, but its spatial representation includes only selected points on the globe. Once having a closer look on information economy, this conclusion is of special importance in the case of its most valuable core: the knowledge-based economy. There are relatively few places within the world economy that play vital role in production of new knowledge, yet they can work close with each other and their output is distributed to all other nodes included in the world network economy.

The above reasoning shows the existence of a distinctive paradox of digital era: ICT potentially being able to overcome spatial barriers (that is to de-concentrate economic activity), lead in reality to refocusing on spatial dimension of business processes and, hypothetically, could lead to their complete concentration. The paradox, if referred to previously listed major characteristics of ICT-economy relationship, shows that lowering the transaction and transportation costs (through low-cost production, storage, transformation and distribution of information) and undertaking economic activity on a distance does not result in decentralization of economic activities. In contrast, ICT embedded in the economy result in spatial concentration and polarization. Business processes are being divided into fragments, but the pattern of this division has a profound spatial dimension - ICT do not contribute to the coming of idealistic global village as predicted some 40 years ago by Marshal McLuhan. Instead, they introduce new, spatial dimension of division of business process and labor that is executed on global level.

One of the contemporary socio-economic phenomena that is described in the literature is the reconfiguration of the geography of economic activity developed under fordist regime of production - hitherto mosaic of separate areas and territories is being transformed into network economy (Scott 1998). The production instead of being organized and executed in single spatial unit is being fragmented, but not necessarily de-concentrated, as shown above. Within this framework, it can be concluded that ICT contribute greatly to this reconfiguration. These technologies allow for the coming of new fragmentation of business processes and new division of labor. The geography of the information revolution does not determine future development prospects, as Hepworth predictions were shown in the passage quoted in the beginning 
of this article. Nevertheless, it definitely changes the spatial organization of economic activity - the information economy is constructed on the basis of selected, geographically separated and distant places, yet strongly linked by the super-territorial flows of information.

\section{REFERENCE}

Carayannis E.G., Sipp C.M., 2006, e-Development Toward the Knowledge Economy. Leveraging Technology, Innovation and Entrepreneurship for "Smart" Development, Palgrave Macmillan, Houndmills - New York.

Castells M., 1989, The Informational City. Information Technology, Economic Restructuring, and the Urban-Regional Process, Basil Blackwell, Oxford.

Foray D., 2004, The Economics of Knowledge, The MIT Press, Cambridge - London.

Hepworth M.E., 1990, Geography of the Information Economy, The Guilford Press, New York - London.

Scholte J.A., 2006, Globalizacja [Globalization; in Polish], Oficyna Wydawnicza Humanitas, Sosnowiec.

Scott A.J., 1998, Regions and the World Economy. The Coming Shape of Global Production, Competition, and Political Order, Oxford University Press, Oxford.

Storper M., 2000, Globalization and Knowledge Economy: An Industrial Geographer's Perspective. [in:] Dunning J.H. (ed.), Regions, Globalization, and the Knowledge-Based Economy, Oxford University Press, Oxford.

World Bank, htp://www.worldbank.org.

Yip G.S., 2004, Strategia globalna [Total Global Strategy; in Polish], Polskie Wydawnictwa Ekonomiczne, Warszawa. 